\title{
Study on Drainage-anchorage Composite Slope Protection System with Pervious Concrete
}

\author{
Wang Bin, Zang Deji, Yang Li \\ Nanjing Hydraulic Research Institute, Nanjing, China \\ Email address: \\ bwang@nhri.cn (Wang Bin)
}

\section{To cite this article:}

Wang Bin, Zang Deji, Yang Li. Study on Drainage-anchorage Composite Slope Protection System with Pervious Concrete. Engineering and Applied Sciences. Vol. 4, No. 5, 2019, pp. 129-134. doi: 10.11648/j.eas.20190405.17

Received: September 3, 2019; Accepted: September 30, 2019; Published: October 17, 2019

\begin{abstract}
In view of the landslide caused by rainfall, a composite structure of seepage guidance and anchorage is proposed. Pervious concrete is used as anchorage cementing material to realize the function of permeability and anchorage. The permeability coefficient, bonding force and cohesion of soil interface were tested. Summarizing the rules of these parameters, we can see that it is feasible to use pervious concrete to realize the composite functional structure. When the porosity is $18 \%$, the comprehensive effect is better. The numerical analysis shows that the composite structure can make the rainfall infiltration line rise slowly and the rock and soil deteriorate slowly, which is beneficial to the stability of the slope. After the rain stops, the characteristics of water and soil in the slope can be restored quickly.
\end{abstract}

Keywords: Permeability-anchorage Structure, Landslide, Pervious Concrete

\section{Drainage-anchorage Composite Slope Protection System}

Landslide is a kind of frequent disaster, and rainfall is one of its important inducements. For rainfall-induced landslides, the process of disaster formation is rainfall-seepage-degradation of geotechnical mechanical parameters-instability. Therefore, on the one hand, reducing sliding force and increasing resistance limit the development of sliding (such as anchorage). On the other hand, from the point of view of disaster chain, seepage conduction can play a role in early pregnancy.
Bolts are buried deep in the soil, and through reasonable design, an ideal seepage passage can be formed. Thus, a composite system of seepage conduction and anchorage is formed to control groundwater in a deep and large area. Therefore, we put forward the idea of drainage-anchorage Composite Slope Protection System [1], and applied for a patent.

The structure can be designed in many forms. Figure 1 is the simplest one. The main components include bolts, permeable cementing materials, bearing plates, etc. The outside of the bolt is filled with pervious cementing material to form a circular pervious belt.

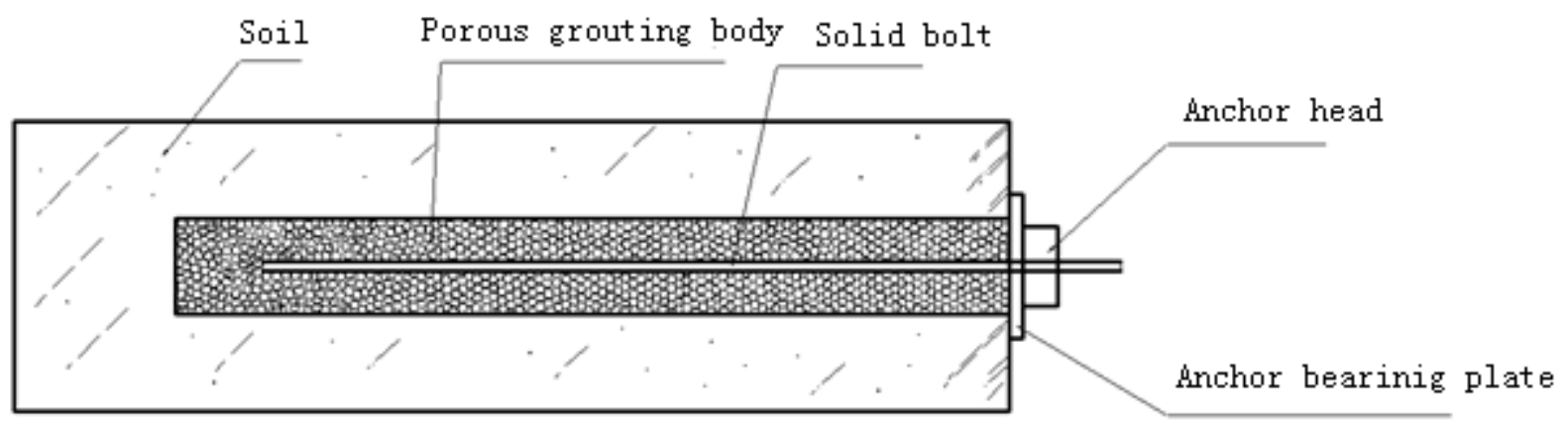

Figure 1. Simple schematic diagram of drainage-anchorage composite structure. 
This paper takes this as the prototype. In the early stage, porous materials are pervious concrete [2] and polyurethane. However, due to the low mechanical properties of polymer concrete, its compressive strength is $1 / 3-1 / 2$ of that of pervious concrete. Therefore, it is decided to choose pervious concrete.

\section{Test of Permeability and Anchorage Performance of Pervious Concrete}

The function of the composite structure includes two aspects: drainage conduction and anchorage. The permeability characteristics mainly depend on the permeability coefficient of porous structure [3, 4]. The anchorage characteristics are mainly reflected in the mechanical properties of the interaction between porous structure and the interface between anchor and rock stratum, while the properties of anchor and cementing material are usually known.

\subsection{Pervious Concrete and Its Porosity}

Pervious concrete is a common silicate cement labeled P. $\mathrm{O} 42.5$, and the aggregate size is $10 \mathrm{~mm}$ to $20 \mathrm{~mm}$. Pervious concrete is formed by two-step feeding and tamping. Curing in the standard maintenance room according to the regulations.

For the measurement of porosity, the samples were soaked in water for 1 hour, and the weight $\mathrm{ml}$ of the samples in water was measured by hanging basket method, then the weight $\mathrm{m}^{2}$ of the samples in air was measured after 24 hours of static drainage. Finally, the formula (1) is applied to calculate the porosity of pervious concrete.

$$
P=\left(1-\frac{m_{2}-m_{1}}{V}\right) \times 100 \%
$$

In the formula, $\mathrm{V}$-specimen volume, $\mathrm{L}$.

\subsection{Pervious Concrete Seepage Characteristics Test}

(1) Measuring method of permeability coefficient

According to the test method of Japan Concrete Association, a permeability meter is designed to measure the permeability coefficient of permeable concrete. The permeability coefficient of pervious concrete specimens is calculated by measuring the drainage in a specified time and using Darcy's law. The permeability coefficient of the specimen is calculated by the following formula.

$$
K_{T}=\frac{1000 L Q}{H A t}
$$

In the formula, $K_{T}$-The permeability coefficient $(\mathrm{mm} / \mathrm{s})$ was measured at water temperature of $\mathrm{T}^{\circ} \mathrm{C}$; L-specimen height $(\mathrm{mm})$; A-Compressed area of permeable structure $\left(\mathrm{mm}^{2}\right)$; Q-The amount of water leaking in t seconds $(\mathrm{ml})$ in the experiment; H-water level difference $(\mathrm{mm})$; t $\mathrm{t}$-test time (s).

(2) Permeability coefficient of pervious concrete

The most important factor affecting the permeability coefficient of permeable concrete is porosity, followed by aggregate size. Other factors have little influence on the permeability coefficient, which can be ignored. Figure 2 shows the permeability coefficient under different porosity conditions.

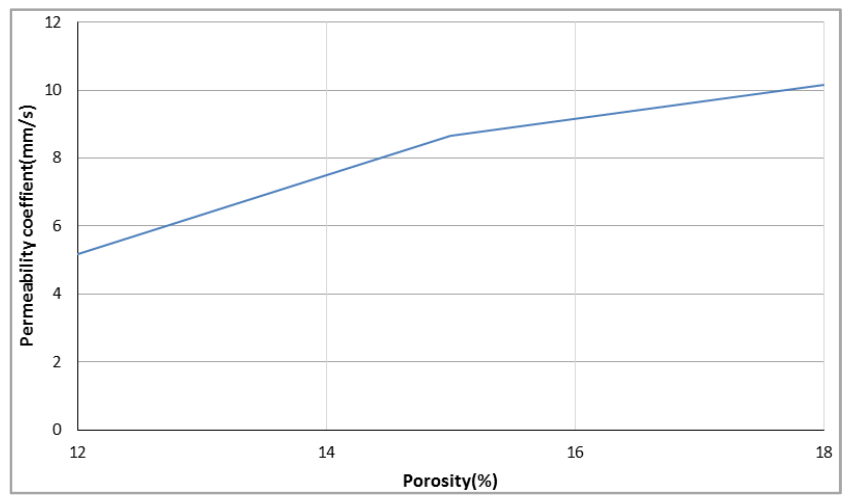

Figure 2. Permeability coefficient of concrete with different porosity.

The larger the permeability coefficient is, the more favorable it is to drain the accumulated water on the slope. The results show that when the aggregate size is $10 \mathrm{~mm}$ to $20 \mathrm{~mm}$ and the porosity is $18 \%$, the permeability coefficient can reach more than $10 \mathrm{~mm} / \mathrm{s}$.

\subsection{Mechanical Properties Test of Anchorage Structure}

In the composite structure of drainage and anchorage, the material and mechanical properties of bolts are known; the mechanical properties of permeable concrete are different from those of conventional concrete, but there are many experimental data available for reference $[5,6]$. Relative uncertainties are manifested in two aspects: 1) the interface between porous permeable cementing materials and anchorage; 2) the interface between porous permeable cementing materials and geotechnical layers.

(1) Strength of Pervious Concrete

Many researchers have tested the strength of pervious concrete [7-9]. There are many factors affecting the strength of pervious concrete, such as porosity, coarse aggregate size and water-cement ratio. Figure 3 shows the test results of compressive and anti-embankment strength with different porosity. Toni universal testing machine was used to test and calculate the mechanical properties of ordinary concrete according to the standard "Standard for Testing Methods of Mechanical Properties of Ordinary Concrete" (GB/T50081-2002).

As can be seen from Figure 3, the strength of pervious concrete decreases to a certain extent. The higher the porosity, the lower the strength. Therefore, in the process of anchorage design, the effect of porosity on strength should be fully considered and high-grade cement should be selected. 


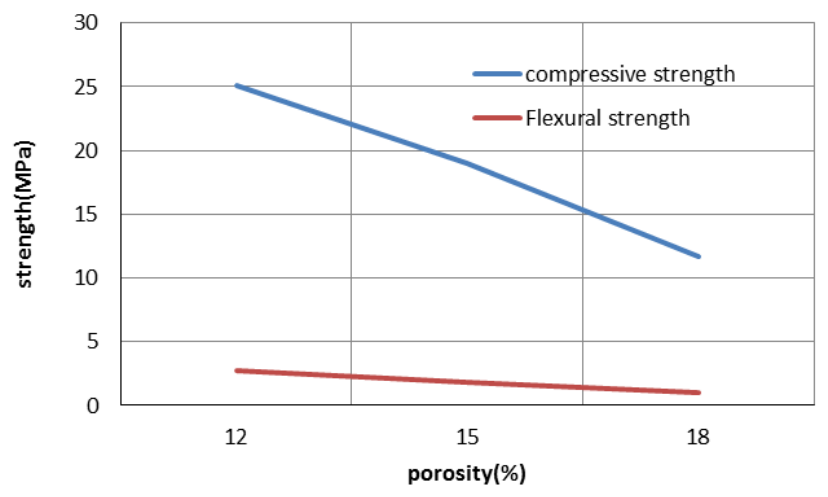

Figure 3. Strength of concrete without porosity.

(2) Bonding force test of pervious concrete

Similar to the bonding strength test of reinforced concrete, $150 \times 150 \times 150 \mathrm{~mm}$ specimens were used. The experiment chooses fiberglass reinforced plastic bolt with a diameter of $20 \mathrm{~mm}$. The anchor bolt and concrete are poured together to form the specimens. The two ends of the bolt are higher than the two ends of the concrete, one end is longer and the other end is shorter. Maintain 28 days after shaping.

The test results are shown in Figure 4. The test block is placed on the bonding force test device. The long end of the bolt is clamped by a universal machine through the central hole of the lower end of the device. Install the micrometer at the shorter end of the bolt and fix it firmly. There are two kinds of experiments, one is dry specimen, the other is wet specimen, which is soaked in water for more than 24 hours.

In order to unify the criteria, Table 1 lists the corresponding grip force values of sliding deformation of $0.1 \mathrm{~mm}$.

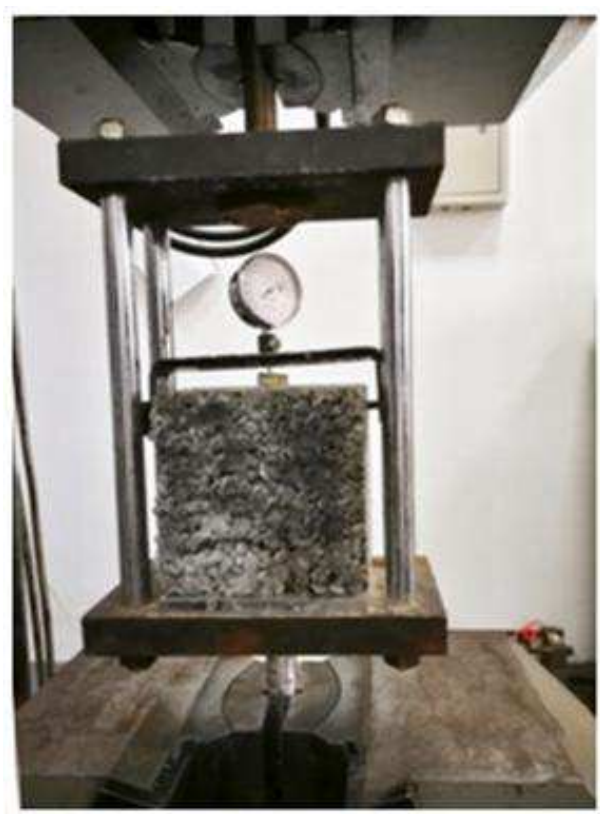

Figure 4. Bonding force test between permeable concrete and bolt.

Table 1. Bonding force measurements at relative slip of $0.1 \mathrm{~mm}$.

\begin{tabular}{|c|c|c|c|c|c|c|}
\hline & \multirow{2}{*}{ Conventional concrete } & \multicolumn{5}{|c|}{ Porosity of Permeable Concrete } \\
\hline & & $9 \%$ & $12 \%$ & $15 \%$ & $18 \%$ & $21 \%$ \\
\hline Test Value of Dry Sample (kN) & 12.50 & 10.75 & 10.73 & 9.20 & 9.83 & 5.50 \\
\hline Test Value of Water Immersed Sample $(\mathrm{kN})$ & 12.85 & 12.60 & 11.00 & 10.47 & 12.06 & 7.03 \\
\hline
\end{tabular}

From the above data, we can see that:

1) The bonding strength of pervious concrete is slightly less than that of conventional concrete.

2) Within a certain range of porosity $(<18 \%)$, the bonding force fluctuates in a certain range, but the relative fluctuation is relatively small, about $75-80 \%$ of the conventional concrete; beyond this range $(>18 \%)$, the bonding force has the possibility of sharp decline.

3) After soaking in water, the bonding force of the sample is slightly larger than that of the dry sample. The analysis shows that the water in the pore of the sample can improve the deformation process under stress.

(3) Contact shear stress with soil

Many researchers have made in-depth studies on the mechanical properties of the interface between structural plane and soil layer $[10,11]$. According to the type of soil studied, there are three main types of contact surface: coarse grained soil and sandy clayey soil.

The change of roughness has obvious effect on the cohesion of the contact surface, but has little effect on the friction angle of the contact surface. Table 2 shows the relationship between roughness and interfacial shear strength of a red clay at normal pressure of 200KP [4, 5]. Sand-filling method is used to measure the depth of sand-filling, that is, the volume of sand-filling divided by the cross-section area $(\mathrm{V} / \mathrm{S})$, which represents the roughness. When the porosity of permeable concrete is $18 \%$, the roughness is $3.18 \mathrm{~mm}$.

It can be seen that the shear strength of the interface increases with the surface roughness. Because of the diversity of rock and soil, the magnitude of increase will be different, which is not discussed here.

Table 2. Effect of Roughness on Contact Shear Stress.

\begin{tabular}{lllllllll}
\hline \multirow{2}{*}{ Normal stress (kPa) } & \multicolumn{2}{l}{ Roughness (mm) } & \multicolumn{1}{l}{$l$} & & & \\
& $\mathbf{0}$ & $\mathbf{0 . 1}$ & $\mathbf{0 . 3 9}$ & $\mathbf{0 . 5 7}$ & $\mathbf{0 . 8 9}$ & $\mathbf{1 . 4 4}$ & $\mathbf{2 . 6 8}$ \\
\hline 100 & 73.44 & 90.84 & 90.32 & 103.44 & 119.00 & 128.48 & 127.52 & 127.36 \\
200 & 116.52 & 133.00 & 147.32 & 169.72 & 172.80 & 177.16 & 181.24 & 191.73 \\
\hline
\end{tabular}

In summary, because the bonding strength of pervious concrete is less than that of conventional concrete, the 
cohesion of concrete-rock interface increases slightly with the surface roughness. Therefore, it is feasible to select suitable grade cement and adopt pervious concrete to realize the function of permeability and anchorage. The specific design parameters can be adjusted slightly according to these rules.

\section{Influences of Drainage-anchorage Composite Structure on Landslide Prevention and Control System}

In order to study the effect of seepage and anchorage composite structure on slope, numerical analysis method was used to simulate the effect of rainfall.

The hypothetical conditions are as follows: 1) the slope height is $6 \mathrm{~m}$, and the slope gradient is $1: 1.333$. At the beginning, the groundwater level is $7 \mathrm{~m}$ on the left and $6 \mathrm{~m}$ on the right. 2) It is a homogeneous soil slope with a soil mass of $18 \mathrm{kN} / \mathrm{m} 3, \quad \mathrm{c}=15 \mathrm{kPa}$, and $\Phi=8^{\circ}$ degree saturated permeability coefficient $\mathrm{k}=1.0 \times 10^{-3} \mathrm{~cm} / \mathrm{s}$. 3) The anchorage system is arranged in three layers, the length of the top bolt is $13 \mathrm{~m}$ and the length of the bottom two bolts is $15 \mathrm{~m}$. The diameter of bolt is $20 \mathrm{~mm}$ and the borehole is $110 \mathrm{~mm}$. 4) Filling porous concrete in annular space with permeability coefficient of $10 \mathrm{~mm} / \mathrm{s}, 5)$ The infiltration per unit area from rainfall is $30 \mathrm{~mm} / \mathrm{h}$, and stops after 24 hours of rainfall.

(1) Change of seepage field

With the rainfall, the water content of the surface soil layer increases rapidly, and the water seeps downward, which leads to the elevation of the infiltration line. Figure 5 shows different saturation lines of slopes with or without drainage function. It can be seen that most slopes are nearly saturated without drainage, as shown in Figure 5 (a). Most of the slope surface of anchorage-seepage protection is still above the infiltration line, as shown in Figure 5 (b).

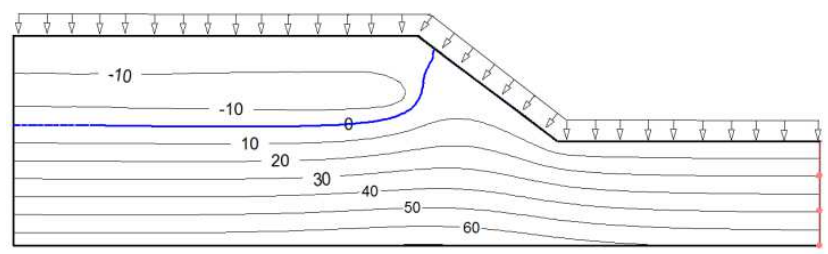

(a)

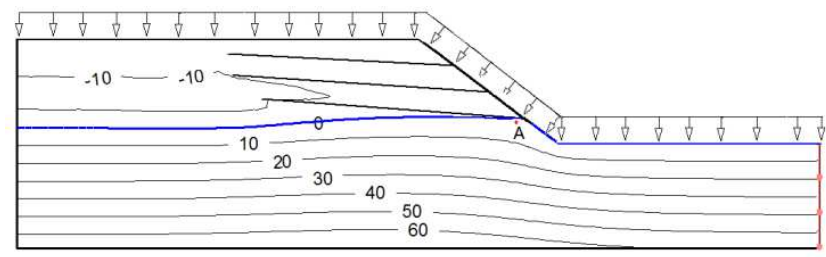

(b)

Figure 5. Difference of slope saturation line after 6 hours of rainfall.

(2) Change process of soil mass

The upper part of slope is unsaturated soil zone and the lower part is saturated soil zone. For unsaturated soils, many scholars have established strength formulas of unsaturated soils with matrix suction as variable, of which Fredlund's bivariate formula is the most famous $[12,13]$. The introduced matrix suction $[6,7]$, also known as negative pore water pressure $[14,15]$.

The research object of feature point A in Figure 5 (b) is selected. Because of the total head of infiltration derivative of rainfall, pore water pressure, water content and pressure head all change, which ultimately leads to the change of mechanical properties of soil and the decrease of its shear strength. Figure 6 the variation of pore water pressure and shear strength of soil with rainfall within 24 hours. Initially, with the infiltration of rainfall, the water content increases, the matrix suction decreases and the shear strength of unsaturated soil decreases. After a certain period of time, A is saturated soil. With the increase of groundwater level in the slope, pore water pressure increases and the shear strength of the soil decreases.

The point is unsaturated-saturated-unsaturated. The corresponding shear strength of soil also changes.

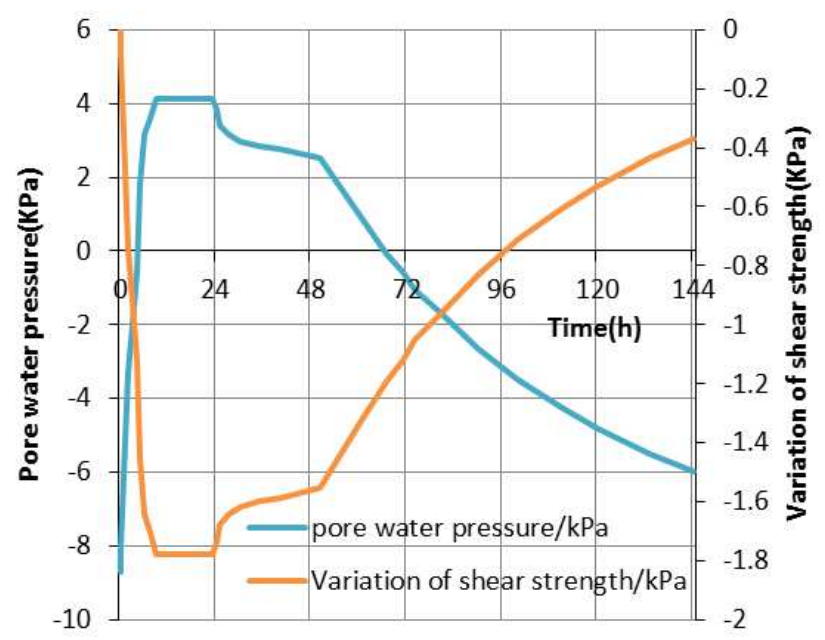

Figure 6. Change of Pore Water Pressure and Soil Shear Strength after Rainfall and Interruption.

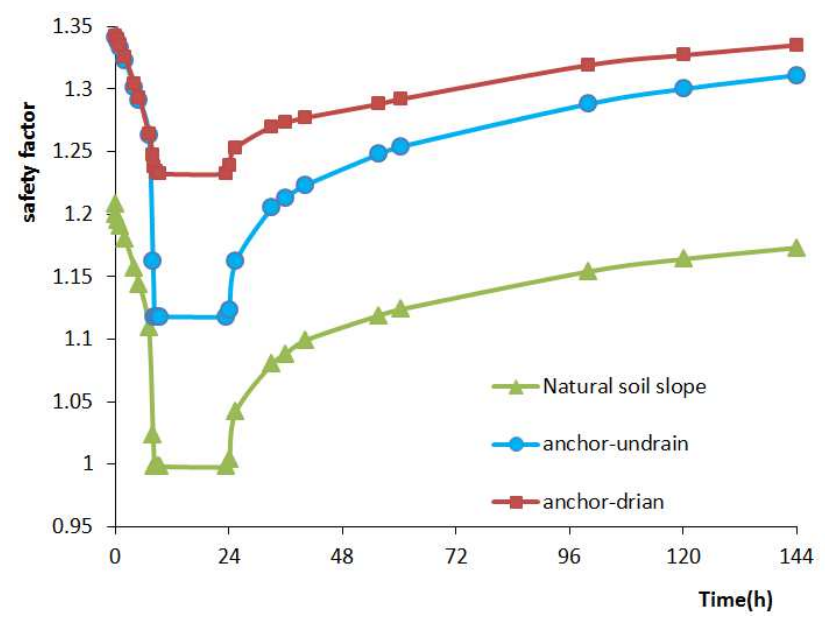

Figure 7. Change of Safety Coefficient after Rainfall and Interruption.

Therefore, the structure with drainage function can alleviate the deterioration of rock and soil strength caused by rainfall, and 
it can also play a role of rapid recovery in the rain stop gap.

(3) Slope stability change

The change of seepage and mechanical properties of soil further affects the stability of slope. Figure 7 is the development process of safety factor after rainfall and interruption. It can be seen that the safety factor of slope decreases with the progress of rainfall, and decreases to the minimum when the seepage field of soil slope reaches a relatively stable state. After rainfall, the safety factor increases gradually with the decrease of water level in soil slope. Anchor slope is similar to natural soil slope.

It can be seen from the comparison curve that: (1) when the stability of natural slope does not meet the requirements, anchorage can improve the stability; (2) in the process of precipitation, without drainage, the reduction of safety factor is larger, with drainage function, the reduction of safety factor is smaller; (3) From the change process, the combination of drainage and anchorage makes the safety factor decrease slowly, the duration of low position is short, and the recovery is fast after the rain stops.

\section{Conclusion}

In order to prevent landslides caused by rainfall, we design seepage mechanism combined with anchorage system to reduce the influence of rainfall seepage on geotechnical strength.

Pervious concrete is chosen as cementing material. The test shows that the bonding force of pervious concrete is slightly less than that of conventional concrete. With the increase of porosity, the permeability coefficient increases and the bonding force decreases. When the porosity is about $18 \%$ and the wrapping force is about $75-80 \%$ of the conventional concrete, the permeability is good and the satisfactory permeability and anchorage effect can be achieved. After soaking in water, its grip force is slightly greater than that in dry state. In addition, the cohesion between permeable concrete and rock-soil interface increases slightly with the roughness of concrete surface.

Therefore, for pervious concrete, the reduction of bonding force is limited, the cohesion of the interface with rock and soil increases, and the permeability performance is good. It is feasible for the composite structure to achieve the purpose of permeability and anchorage.

The numerical study shows that the composite structure system of seepage guidance and anchorage can not only reinforce the slope, but also discharge a large amount of seepage through the permeable material. It can effectively reduce the height of saturation line and pore water pressure of soil, thereby reducing the deterioration of rock mechanics properties caused by water immersion. The safety factor of slope stability decreases when rain falls, and recovers quickly after rain stops. It can cushion and damp landslide catastrophe, and take both the specimen and the treatment effect.

\section{Acknowledgements}

This project is supported by the National Key R \& D
Program of China (2017YFC0405005/2016YFC0401610).

\section{References}

[1] Wang Bin, Zang Deji, and Hu lianghao. Study on Mechanism of drainage-anchorage Composite Slope Protection System, Proceedings of the 2017 2nd international Conference on Civil, Transportation and Environmental Engineering [C], Shenzhen: AER 135 (2017): 106-112.

[2] Song Zhong Nan, Shiyunxing. Permeable concrete and its application technology. Beijing: China Construction Industry Press. 2011.

[3] Maryam Saaly, Mohammad, et al. Performance of pervious concrete pavement under various raining conditions [J]. Road Materials and Pavement Design. 2019, 20 (7): 1525-1547.

[4] K. S. Elango, V. Revathi. Infiltration and clogging characteristics of pervious concrete [J]. Asian Journal of Civil Engineering, 2019, 20 (8): 1119-1127.

[5] Xinzhuang Cui; Jiong Zhang. Experimental Study on the Relationship between Permeability and Strength of Pervious Concrete. Journal of Materials in Civil Engineering [J]. Volume 29, Issue 11, 2017, Pages 1-9.

[6] Zhang Jiong, Ming Ruiping, et al. Review on permeability property and clogging of pervious concrete [J]. Concrete, 2019, 7 (Tot No. 357): 94-99.

[7] Hunag Guoyang, Xu Haofeng, et al. Optimization design of mixture proportion of cement-based pervious concrete $[\mathrm{J}]$. Journal of Ningbo university (NSEE), 2019, 32 (5): p 59-64.

[8] Cheung Kwok Keung. Study on experimental performance of pervious concrete [D]. Guangzhou, Guangzhou University, 2018.

[9] Anush K. Chandrappa; Krishna Prapoorna Biligiri. Effect of pore structure on fatigue of pervious concrete $[\mathrm{J}]$. Road Materials and Pavement Design, 2019, No. 7: 1525-154.

[10] Li Jian. The Relationship between Roughness and Mechanical Properties of Clay-Concrete Structure Interface [D]. Changsha: Central South University, 2014.

[11] Yang Su-chun, Zhang Ming-yi, et al. Study on mechanical test of interface between clay and concrete based on the tribology theory of adhesion and ploughing [J]. Journal of Guangxi University (Nat Sci Ed), 2019, 44 (4): 1021-1030.

[12] Ning Lu, William J. Likos. Mechanics of unsaturated soilsm [M], Wei Chang Fu, Beijing: Higher Education Press. 2012.

[13] Wang Sihai, Wang Xudong, Li Yuhan. Experimental study on shear strength of unsaturated soils based on matric suction [J]. Journal of Nanjing tech universty (Natural Science Edition) 2017, 39 (4): 118-123.

[14] Qin Wenshuai; Li Guangfan. Effects of Saturation on Shear Strength of Unsaturated Silty Clay [J]. Natural Science Journal of Hainan University, 2016, No. 3 270-277.

[15] Cao Zhixiang, Han Xiandong, et al. Experimental study on the effect of moisture content on shearstrength of unsaturated sandy soil $[\mathrm{J}]$. Journal of henan polytechnic university (Natural science). 2019, 38 (5): 159-164. 


\section{Biography}

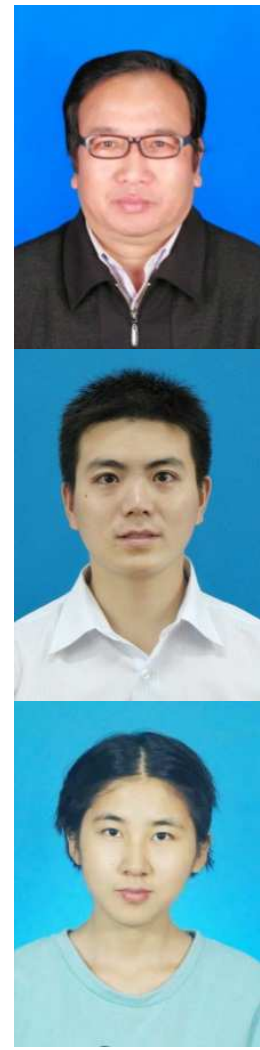

Wang Bin was born in March 1964. He graduated from China University of Mining and Technology in January 1995 with a PhD in Engineering. He works in Nanjing hydraulic research institute. He is the chief engineer of the Institute of Materials and Structures. His title is Professor. He is engaged in the research of disaster prevention and hidden danger detection in the specialty of hydraulic structure.

Zang Deji was born in 1981. He graduated from Hohai University with a major in hydraulic structure engineering in 2008. His title is senior Engineer. He is engaged in research on inspection and evaluation of water conservancy projects.

Yang Li was born in November 1996. I graduated from Changsha University of Science and Technology with a bachelor's degree. Now I am a postgraduate majoring in hydraulic structure engineering at Nanjing Hydraulic Research Institute. At present, I am mainly engaged in the research on hidden danger detection of structural engineering. 